\title{
Intraoperative use of transcranial motor/sensory evoked potential monitoring in the clipping of intracranial aneurysms: evaluation of false-positive and false-negative cases
}

\author{
Jaewoo Chung, MD, ${ }^{1}$ Wonhyoung Park, MD, ${ }^{1}$ Seok Ho Hong, MD, PhD,1 Jung Cheol Park, MD,1 \\ Jae Sung Ahn, MD, PhD, ${ }^{1}$ Byung Duk Kwun, MD, PhD, ${ }^{1}$ Sang-Ahm Lee, MD, PhD, ${ }^{2}$ \\ Sung-Hoon Kim, MD, PhD, ${ }^{3}$ and Ji-Ye Jeon, MD ${ }^{2}$
} Departments of ${ }^{1}$ Neurosurgery, ${ }^{2}$ Neurology, and ${ }^{3}$ Anesthesiology and Pain Medicine, University of Ulsan College of Medicine,
Asan Medical Center, Seoul, Korea

\begin{abstract}
OBJECTIVE Somatosensory and motor evoked potentials (SEPs and MEPs) are often used to prevent ischemic complications during aneurysm surgeries. However, surgeons often encounter cases with suspicious false-positive and falsenegative results from intraoperative evoked potential (EP) monitoring, but the incidence and possible causes for these results are not well established. The aim of this study was to investigate the efficacy and reliability of EP monitoring in the microsurgical treatment of intracranial aneurysms by evaluating false-positive and false-negative cases.

METHODS From January 2012 to April 2016, 1514 patients underwent surgery for unruptured intracranial aneurysms (UIAs) with EP monitoring at the authors' institution. An EP amplitude decrease of $50 \%$ or greater compared with the baseline amplitude was defined as a significant EP change. Correlations between immediate postoperative motor weakness and EP monitoring results were retrospectively reviewed. The authors calculated the sensitivity, specificity, and positive and negative predictive values of intraoperative MEP monitoring, as well as the incidence of false-positive and false-negative results.
\end{abstract}

RESULTS Eighteen (1.19\%) of the 1514 patients had a symptomatic infarction, and $4(0.26 \%)$ had a symptomatic hemorrhage. A total of 15 patients showed motor weakness, with the weakness detected on the immediate postoperative motor function test in 10 of these cases. Fifteen false-positive cases $(0.99 \%)$ and 8 false-negative cases $(0.53 \%)$ were reported. Therefore, MEP during UIA surgery resulted in a sensitivity of 0.10 , specificity of 0.94 , positive predictive value of 0.01 , and negative predictive value of 0.99 .

CONCLUSIONS Intraoperative EP monitoring has high specificity and negative predictive value. Both false-positive and false-negative findings were present. However, it is likely that a more meticulously designed protocol will make EP monitoring a better surrogate indicator of possible ischemic neurological deficits.

https://thejns.org/doi/abs/10.3171/2017.8.JNS17791

KEY WORDS unruptured intracranial aneurysms; evoked potential; false negative; false positive; diagnostic technique; vascular disorders

$\mathrm{M}$ ICROSURGERY for unruptured intracranial aneurysms (UIAs) should be performed carefully, as patients with UIAs are usually asymptomatic or have minimal neurological deficits. Previous studies have reported that overall morbidity rates of surgery for UIAs range between $2.2 \%$ and $13.7 \%, 1,3,18,36,47,67$ with ischemic complications being a major cause of morbidity. $5,9,36,41,54,59$ Thus, preventing ischemic complications during UIA surgery should reduce the morbidity rate.

Currently, various methods are used for preventing is-

ABBREVIATIONS $\mathrm{AChA}=$ anterior choroidal artery; DSA = digital subtraction angiography; EP = evoked potential; GOS = Glasgow Outcome Scale; ICG = indocyanine green; $\mathrm{ICH}$ = intracerebral hemorrhage; MEP = motor evoked potential; $\mathrm{mRS}$ = modified Rankin Scale; MVD = microvascular Doppler; NMB = neuromuscular blockade; $\mathrm{NPV}=$ negative predictive value; $\mathrm{PPV}=$ positive predictive value; $\mathrm{SAH}=$ subarachnoid hemorrhage; $\mathrm{SDH}$ = subdural hemorrhage; $\mathrm{SEP}=$ somatosensory evoked potential; $\mathrm{UIA}=$ unruptured intracranial aneurysm. 
chemic complications during aneurysm surgery, including intraoperative CT, MRI, digital subtraction angiography (DSA), microvascular Doppler (MVD) sonography, indocyanine green (ICG) videoangiography, and neurophysiological monitoring. ${ }^{2}$ Among these methods, intraoperative neurophysiological monitoring, including monitoring of somatosensory evoked potentials (SEPs) and motor evoked potentials (MEPs), has become more common and is often considered a predictor of neurological functional outcomes. ${ }^{12,20-22,29,37,39,44,58,60,63,69}$ Previous MEP/SEP studies were primarily focused on sensitivity and specificity, which represents their efficacy in monitoring. However, when using intraoperative evoked potential (EP) monitoring, surgeons often encounter both false-positive cases and false-negative cases. Unfortunately, the incidence and potential causes of these events are not well established. Therefore, the purpose of this study was to evaluate the sensitivity, specificity, positive predictive value (PPV), negative predictive value (NPV), and incidences of falsepositive and false-negative results in patients who underwent surgery for UIAs. Furthermore, possible factors for false-positive and false-negative results during intraoperative transcranial EP monitoring are discussed.

\section{Methods}

This retrospective study was approved by the institutional review board of Asan Medical Center.

All cases in which patients with UIAs underwent microsurgical treatment involving aneurysm clipping with intraoperative EP monitoring between January 2012 and April 2016 were reviewed. Patients with any additional intracranial pathology or with neurological deficits were excluded from the study to minimize confounding effects on monitoring. Each patient's medical records included patient characteristics, aneurysm location, anesthetic regimen, surgical method, any neurological deficits, any perioperative complications, clinical outcomes, medical history, baseline and intraoperative EP results, and radiological images. All surgeries were performed by 2 experienced neurosurgeons. UIAs were microsurgically treated with aneurysm neck clipping with additional trapping with or without bypass surgery if needed, according to interdisciplinary consensus. A temporary clip was applied to the parent artery for up to 3 minutes when proximal blood flow control was needed during surgery, with at least a 5-minute interval between episodes of temporary clipping. The temporary clip was removed as soon as possible whenever there was a significant EP change. Immediate postoperative neurological examinations included mental status assessment, a motor function test, and a basic cranial nerve function test performed by the neurosurgeons when the patient arrived in the intensive care unit. Immediate postoperative brain CT, CT angiography, and perfusion CT were performed with a CereTom mobile CT scanner (Neurologica) before extubation in the operation room, or a conventional CT scan with CT angiography was performed as soon as possible after extubation. Routine follow-up brain CT was performed 3 days postoperatively. A brain MRI (with or without diffusion-weighted sequences) or DSA was performed if the patient presented with neurological deficits or if there might have been a violation of the parent artery during the surgery. Patients' functional status was assessed with the Glasgow Outcome Scale ${ }^{28}$ at discharge and with the modified Rankin Scale (mRS) ${ }^{55} 6$ months postoperatively for the evaluation of clinical outcomes.

\section{Anesthesia Regimen}

Total intravenous anesthesia was used in all cases, and the standard American Society of Anesthesiologists guidelines were followed. Anesthesia was induced with propofol $(1.5-2.5 \mathrm{mg} / \mathrm{kg}$ ), followed by total intravenous anesthesia using a commercially available 2-channel target-controlled infusion pump (Orchestra; Fresenius Vial). Anesthesia was maintained using continuous infusion of propofol $(2.5 \mathrm{mg} / \mathrm{ml})$ and remifentanil $(7-9 \mathrm{ng} / \mathrm{ml})$ before opening the dura, and the infusions were increased to 3.0 $\mathrm{mg} / \mathrm{ml}$ and $15 \mathrm{ng} / \mathrm{ml}$, respectively, after opening the dura. The depth of anesthesia was monitored using a Bispectral Index (BIS system; Covidien; range 40-50).

During the study period, there was a protocol shift involving the use of neuromuscular blockades (NMBs; rocuronium or vecuronium) during surgery with EP monitoring. The tendency to use NMBs gradually decreased during the study period. Therefore, we categorized patients into 2 groups: those given a continuous low-dose NMB throughout surgery (cNMD group) and those who received a single NMB bolus injection during the intubation process for anesthesia (sNMB group).

\section{EP Monitoring}

In all cases, preoperative SEP evaluation was performed the day before surgery with a Neuropack MEB-2200 (Nihon Kohden). From this evaluation, the baseline SEP and any abnormal amplitude or latency that existed preoperatively could be determined. These EP results constituted the baseline reference and were used during intraoperative monitoring. Preoperative MEP evaluation was not considered because of the pain caused by electrical stimulation during the evaluation. The same device was used for intraoperative EP monitoring, which was performed by trained neurophysiologists. All electrodes were placed bilaterally, allowing the EP results of the ipsilateral side to be used as a reference to reduce the chance of alterations due to surgical procedures. Subcutaneous, bilateral placement of cranial electrodes at $\mathrm{C} 3 / \mathrm{C} 4$ was performed for both MEP and SEP monitoring according to the International 10-20 system.

For MEP monitoring, a train of 6 constant-current anodal 0.5-msec-wide stimuli delivered at 3-msec interstimulus intervals was used to obtain MEP waves. Bilateral MEPs were recorded using patch electrodes at the tibialis anterior, adductor hallucis, and abductor pollicis brevis muscles based on the aneurysm location. MEPs were recorded within a $150-\mathrm{msec}$ interval with filtration and amplification (bandpass 30-2000 Hz, 10,000 times). The baseline stimulus intensity was tested a minimum of 3 times before the intradural procedure (before scalp incision, craniotomy, and dura incision), and a minimal stimulus intensity was used until EP responses were detectable in the lower extremities. Once the baseline intensity was 
established, the baseline amplitudes of MEP/SEP waves were chosen and documented in the neurophysiology event $\log$. SEP results from the bilateral median and tibial nerves were monitored throughout the surgery based on the location of the aneurysm. SEP results were detected from the cranial electrode following continuous stimulation with a $4.7-\mathrm{Hz}$ current at minimal stimulus intensity.

Various methods of defining alert criteria have been discussed in previous studies, with the majority of authors suggesting that a decrease in amplitude of greater than $50 \%$ be considered the clinical warning sign. . $^{13,22,25,26,37,57,63,}$ ${ }^{64,69}$ Thus, we applied this criterion, and when any such reduction occurred, the neurophysiology team immediately shared the EP results with the surgeon. MEP stimulation was routinely performed after clipping. Additional stimulation was performed upon SEP decline, at the surgeon's request, and at skull closure. The final EP monitoring was performed during scalp closure, using MEPs. If there was change in the EP results, the stimulation intensity was gradually increased and checked repeatedly. The stimulation intensity was kept below $300 \mathrm{~V}$ to avoid false-negative results.

As mentioned above, if an EP change met the alert criterion, the neurophysiologist immediately warned the surgeon. We usually follow several steps to find the cause of EP change. First, we stop the procedure and search for the possible cause of ischemia by careful inspection. Second, MVD sonography is performed to verify the blood flow around the parent artery and surrounding perforators. Cortical artery blood flow is also checked to identify any subtle decrease in blood flow. This procedure is usually performed within 1 minute of the EP change. If there is a notable decrease in blood flow, release of the temporary or permanent clip usually leads to recovery of EP results. If the EP results do not recover, we replace the CSF lost with normal saline and tilt the patient's head toward the neutral position. Placing saline-soaked cotton into the subdural space can also be helpful. Additional ICG videoangiography could be considered for confirming patency in this situation. Despite these methods, EP changes could still meet the alert criterion; at this point, the surgeon must decide whether to proceed with the surgery.

\section{Definition of False Negative and False Positive}

Evoked potential monitoring is a neurophysiological measurement of corticospinal tract (MEPs) and spinothalamic tract (SEPs) function. To identify false-negative and false-positive results, the proper neurological examination should be a motor function test for MEPs and a sensory function test for SEPs. ${ }^{24}$ However, there is a limitation of evaluation of sensory function in immediate postoperative circumstances. Thus, positive findings in terms of functional outcome were defined as any grade of motor weakness or asymmetry in the immediate postoperative motor function test. Because this definition is based on normal motor function, false-negative cases were defined as patients who had no significant EP change during the surgery but had localized motor weakness or asymmetry in their immediate postoperative motor function test due to a newly developed brain lesion identified from brain CT or MRI. Significant MEP or SEP events were categorized as persistent EP changes until final stimulation (analyzed as persistent MEP changes or persistent SEP changes) or any form-episodic or persistent-of EP change (analyzed as any MEP change or any SEP change).

Unlike false-negative cases, defining false-positive cases is relatively complicated. Intraoperative EP changes are considered a surrogate indicator for ischemic injury, although significant EP changes are not always associated with brain infarction or motor weakness. ${ }^{21}$ Moreover, brain infarctions may be asymptomatic. Without tractography data, it is often hard to determine whether a brain infarction involves the corticospinal tract. Additionally, interpretation of a recovered EP change may suggest some potential recovery of motor functions. Thus, we defined false-positive cases as those in which patients had a persistent significant EP change until the completion of EP monitoring but did not develop any postoperative motor weakness or new ischemic brain lesions.

\section{Statistical Analysis}

Sensitivity, specificity, PPV, and NPV were calculated with a Blaker exact 95\% confidence interval using the "PropCIs" package in R software version 3.1.0 for Windows (R Foundation for Statistical Computing). ${ }^{16}$ A Pearson test, Spearman-rho test, and univariate and multivariate logistic regression analyses were used for risk factor analysis for false-positive and false-negative cases using commercial software (IBM SPSS Statistics, version 22; IBM Corp.).

\section{Results}

From January 2012 to April 2016, 1571 patients without neurological deficits underwent surgical treatment of a total of 1902 UIAs. Fifty-seven patients who underwent UIA surgery (1 UIA each) without EP monitoring were excluded. Therefore, data from 1514 patients who underwent treatment of 1845 UIAs were analyzed in this study. Patient demographic data and aneurysm characteristics are presented in Table 1. The majority of the aneurysms were treated by aneurysm neck clipping (1843 aneurysms in 1512 patients); there was 1 case each of clipping with bypass and trapping (which included clipping) with bypass. There were 1392 patients in the cNMB group and 122 patients in the sNMB group. No statistically significant difference was found between the 2 groups with respect to patient characteristics, aneurysm location, operating method, complication rates, functional outcome, radiological outcome, or the rate of false positives or false negatives.

There were 6 patients with a Glasgow Outcome Scale (GOS) score of 4 (moderate disability) at discharge $(0.40 \%)$. Evaluation of mRS scores obtained 6 months postoperatively showed that 1 patient $(0.07 \%)$ had a score of 3,2 patients $(0.13 \%)$ had a score of 2 , and 7 patients $(0.46 \%)$ had a score of 1 , while the remaining patients had a score of 0 (no symptoms). Overall, complications were identified in 75 patients (4.95\%), with 36 patients (2.38\%) having morbidity at their 6-month follow-up evaluation. A summary of complications is presented in Table 2. The leading cause of complications was a newly developed infarction found on brain CT or MRI within 3 days of 
TABLE 1. Summary of clinical and demographic data and aneurysm characteristics for 1514 patients who underwent clipping of 1845 UIAs with EP monitoring

\begin{tabular}{|c|c|}
\hline Variable & Value \\
\hline \multicolumn{2}{|l|}{ Sex, n (\%) } \\
\hline Female & $1061(70.08 \%)$ \\
\hline Male & $453(29.92 \%)$ \\
\hline Mean age in yrs & $57.14 \pm 9.30$ \\
\hline Hypertension, n (\%) & $150(9.91 \%)$ \\
\hline $\mathrm{DM}, \mathrm{n}(\%)$ & $747(49.34 \%)$ \\
\hline History of CAD, $n(\%)$ & $29(1.92 \%)$ \\
\hline Mean aneurysm size in $\mathrm{mm}$ & $4.80 \pm 3.38$ \\
\hline \multicolumn{2}{|c|}{$\begin{array}{l}\text { Aneurysm location, }{ }^{*} \mathrm{n}(\%), \text { mean } \\
\text { size in } \mathrm{mm}\end{array}$} \\
\hline \multicolumn{2}{|l|}{ Anterior circulation } \\
\hline \multicolumn{2}{|l|}{ ICA } \\
\hline Cavernous & $2(0.11 \%), 23.00 \pm 8.28$ \\
\hline Paraclinoid & $145(7.86 \%), 5.91 \pm 4.21$ \\
\hline PCoA & 209 (11.33\%), $4.87 \pm 3.00$ \\
\hline $\mathrm{AChA}$ & $143(7.75 \%), 3.27 \pm 1.65$ \\
\hline ICA bifurc & $85(4.61 \%), 6.91 \pm 7.51$ \\
\hline $\mathrm{ACoA}$ & $324(17.56 \%), 4.89 \pm 2.60$ \\
\hline ACA & $98(5.31 \%), 4.13 \pm 4.57$ \\
\hline MCA & $792(42.93 \%), 4.60 \pm 2.58$ \\
\hline \multicolumn{2}{|l|}{ Posterior circulation } \\
\hline Basilar top & $19(1.03 \%), 4.71 \pm 2.92$ \\
\hline PCA & $2(0.11 \%), 2.50 \pm 0.28$ \\
\hline SCA & $13(0.70 \%), 4.08 \pm 2.72$ \\
\hline AICA \& PICA & $13(0.70 \%), 5.62 \pm 3.50$ \\
\hline
\end{tabular}

$\mathrm{ACA}=$ anterior cerebral artery; $\mathrm{ACOA}=$ anterior communicating artery; $\mathrm{AICA}$ $=$ anterior inferior cerebellar artery; bifurc $=$ bifurcation; $C A D=$ coronary artery disease; $\mathrm{DM}=$ diabetes mellitus; $I C A=$ internal carotid artery; $\mathrm{MCA}=$ middle cerebral artery; $\mathrm{PCA}=$ posterior cerebral artery; $\mathrm{PCoA}=$ posterior communicating artery; PICA = posterior inferior cerebellar artery; SCA = superior cerebellar artery.

Data are from 1514 patients who underwent clipping of 1845 UIAs with EP monitoring. Means are presented with SDs.

* Aneurysm location indicates the originating artery of the aneurysm sac.

surgery and confirmed by an experienced radiologist; this occurred in 72 cases, with the patients showing symptoms in $18(25 \%)$ of these cases and being asymptomatic in the remaining 54 cases (75\%). Symptoms of the infarctions were motor weakness (in 10 cases), confusion or delirium (in 5 cases), aphasia or dysphasia (in 2 cases), and syndrome of inappropriate antidiuretic hormone secretion (in 1 case). In an additional 4 cases, the patients had brain hemorrhage, and in another case the patient had perfusion delay (Table 2).

The most important symptom correlating with an abnormal MEP result was motor weakness. A total of 15 patients showed motor weakness; in 10 of these patients, it was detected on the immediate postoperative motor function test, and in the remaining 5 it was observed several hours after the immediate postoperative motor function test. Causes for the immediate motor weakness were in-
TABLE 2. Clinical and radiological outcome

\begin{tabular}{cc}
\hline Variable & No. of Cases $(\%)$ \\
\hline Complications & $75(4.95)$ \\
\hline Radiologically confirmed infarction & $72(4.76)$ \\
\hline Asymptomatic infarction & $52(3.43)$ \\
\hline Symptomatic infarction & $18(1.19)$ \\
\hline Motor weakness & $9(0.59)$ \\
\hline Confusion/delirium & $5(0.33)$ \\
\hline Motor/sensory aphasia & $2(0.13)$ \\
\hline Delayed infarction (after POD 3) & $2(0.13)$ \\
\hline Hemorrhage & $4(0.26)$ \\
\hline ICH \& SAH & $1(0.07)$ \\
\hline ICH & $2(0.13)$ \\
\hline EDH & $1(0.07)$ \\
\hline CN III palsy & $3(0.20)$ \\
\hline Seizure & $2(0.13)$ \\
\hline Vasospasm & $2(0.13)$ \\
\hline Other & $9(0.59)$ \\
\hline Functional outcomes & $6(0.40)$ \\
\hline GOS <5 at discharge & $1(0.07)$ \\
\hline mRS $\geq 3$ at 6 mos &
\end{tabular}

$\mathrm{CN}=$ cranial nerve; $\mathrm{EDH}=$ epidural hemorrhage; $\mathrm{POD}=$ postoperative day. Some patients had more than 1 type of complication and are therefore represented in more than 1 category.

farction (8 cases) and intracerebral hemorrhage (ICH) with subarachnoid hemorrhage (SAH) (1 case). One of the 8 patients with infarction had a persistent significant EP change, which was a true positive (i.e., this case did not fit the criteria for false positive or false negative). The remaining patient with immediate postoperative motor weakness had decreased blood flow on perfusion CT without having demonstrated any EP change during surgery. DSA was immediately performed and revealed parent artery stenosis due to aneurysm neck clipping. Repeat surgery was performed for clip repositioning after the DSA, and the patient did not have a brain infarction. This patient was excluded from the false-negative cases, as there was no newly developed brain lesion on postoperative imaging.

None of the 5 patients with delayed motor weakness had any EP change during surgery. Delayed motor weakness was caused by postoperative hematomas, such as epidural or subdural hemorrhages. In the remaining 2 cases, it was caused by brain infarction, which occurred 4 and 9 days postoperatively, respectively. Neither of these patients exhibited any motor weaknesses during their immediate postoperative neurological function tests. However, they both had an acute infarction in a clip-related territory. One had an acute infarction in the right anterior choroidal artery (AChA) territory during clipping of a posterior communicating artery aneurysm, and the other had an acute infarction in the right frontal region from the right $\mathrm{A}_{2}-\mathrm{A}_{3}$ junction aneurysm clipping. We presumed that brain expansion and restoration of CSF led to aneurysm clip torsion or rotation, leading to compromised blood flow of the adjacent arteries. 
TABLE 3. False-positive cases

\begin{tabular}{|c|c|c|c|c|c|c|c|c|c|c|c|}
\hline \multirow{2}{*}{$\begin{array}{l}\text { Case } \\
\text { No. }\end{array}$} & \multirow{2}{*}{$\begin{array}{l}\text { Age (yrs), } \\
\text { Sex }\end{array}$} & \multicolumn{2}{|c|}{ Aneurysm Characteristics } & \multirow{2}{*}{$\begin{array}{l}\text { Muscle } \\
\text { Relaxant }\end{array}$} & \multicolumn{2}{|c|}{ MEP Cx } & \multicolumn{2}{|c|}{ SEP Cx } & \multirow{2}{*}{$\begin{array}{c}\text { Postop Motor } \\
\text { Weakness }\end{array}$} & \multirow[b]{2}{*}{ GOS† } & \multirow[b]{2}{*}{ mRS $\ddagger$} \\
\hline & & Location* & Size $(m m)$ & & Persist & Any & Persist & Any & & & \\
\hline 1 & $52, \mathrm{~F}$ & PCoA & 4 & Contin & + & + & - & - & - & 5 & 0 \\
\hline 2 & $46, \mathrm{~F}$ & $\mathrm{ACoA}$ & 6.3 & Contin & + & + & - & - & - & 5 & 0 \\
\hline 3 & $69, \mathrm{~F}$ & $\mathrm{ACo} A$ & 1.7 & Contin & + & + & - & - & - & 5 & 0 \\
\hline 4 & $56, F$ & MCA & 3.6 & Single bolus & + & + & - & - & - & 5 & 0 \\
\hline 5 & $38, F$ & $\mathrm{ACoA}$ & 5 & Contin & + & + & - & - & - & 5 & 0 \\
\hline 6 & $65, \mathrm{M}$ & MCA & 2.06 & Contin & + & + & - & - & - & 5 & 0 \\
\hline 7 & $56, \mathrm{M}$ & $\mathrm{ACoA}$ & 5.8 & Single bolus & + & + & - & - & - & 5 & 0 \\
\hline 8 & $55, \mathrm{~F}$ & MCA & 3.2 & Contin & + & + & + & + & - & 5 & 0 \\
\hline 9 & $60, F$ & MCA & 5.3 & Contin & + & + & - & - & - & 5 & 0 \\
\hline 10 & $54, \mathrm{M}$ & MCA & 3.7 & Contin & + & + & - & - & - & 5 & 0 \\
\hline 11 & $53, \mathrm{M}$ & MCA & 2.3 & Single bolus & + & + & - & - & - & 5 & 0 \\
\hline 12 & $47, \mathrm{M}$ & MCA & 3 & Contin & + & + & - & - & - & 5 & 0 \\
\hline 13 & $43, M$ & MCA & 2.4 & Contin & + & + & - & - & - & 5 & 0 \\
\hline 14 & $56, F$ & ACA & 4.58 & Contin & + & + & - & - & - & 5 & 0 \\
\hline 15 & $61, M$ & $\mathrm{ACo} A$ & 2 & Single bolus & + & + & - & - & - & 5 & 0 \\
\hline
\end{tabular}

Contin = continuous; $\mathrm{Cx}=$ change(s); persist = persistent; + = EP change event; - = no EP change event.

* Aneurysm location indicates the originating artery of the aneurysm sac.

$\dagger$ GOS score at discharge.

$\ddagger$ mRS score at 6 months' follow-up.

The current study had a total of 15 cases with falsepositive findings and 8 with false-negative findings. In all cases with false-positive findings, there were persistent MEP changes, but none of the patients showed motor weakness postoperatively. In contrast, the patients in the 8 cases with false-negative findings showed motor weakness upon immediate postoperative neurological examination. However, they did not have any specific EP changes during the surgery. The incidence of false-positive findings was $0.99 \%$, and that for false-negative findings was $0.53 \%$ (Tables 3 and 4).

Because persistent EP change and an episodic EP change event have the potential to raise different clinical issues, we calculated the sensitivity, specificity, PPV, and NPV for persistent MEP changes, persistent SEP changes, any MEP change, any SEP change, and overall EP changes to compare the differences. All analyses showed high specificity (0.941-0.995) and NPVs (0.993-0.994), with low sensitivity (0.000-0.100) and PPVs (0.000-0.011) (Table 5). A subanalysis was also conducted to determine whether any group benefited more from EP monitoring based on sex, age, size of aneurysm, aneurysm location, and multiplicity of aneurysms. However, because of the low incidence of false-positive and false-negative cases, there were no statistically significant findings.

Three illustrative cases are presented in Figs. 1-3.

\section{Discussion}

Complications from microsurgical treatment of UIAs include ischemic brain injury, hemorrhage, hydrocephalus, and seizure. $1,3,4,6,7,18,27,31,32,35,36,40,47,67$ Ischemic brain injury is one of the most common complications of UIA surgery and is reported to occur in $13.2 \%$ of surgically treated patients with UIAs. The cause of ischemic brain injury is associated with surgical maneuvers, physiological conditions, anesthesia, and postsurgical complications. ${ }^{15,34,39,45,48,52,66}$ Surgical maneuvers that may violate cerebral blood flow and are susceptible to control include clipping the aneurysm neck, prolonged temporary clipping of the parent artery, retraction with a spatula, or causing direct injury to a perforating artery. $39,46,50,51,56$

To avoid ischemia due to surgical events, various intraoperative monitoring methods have been employed, including intraoperative CT, MRI, DSA, MVD sonography, ICG videoangiography, and neurophysiological monitoring. ${ }^{2}$ Among these methods, measurement of MEPs and SEPs has the advantage of being relatively less invasive and less expensive; moreover, MEPs and SEPs can be measured throughout the surgery with continuous or intermittent monitoring. EP monitoring can also detect both superficial and deep ischemic brain lesions. ${ }^{2}$ However, there is also a chance of complications associated with EP monitoring; patients may experience seizure, tongue and lip lacerations, mandibular fracture, cardiac arrhythmia, and intraoperative awareness..$^{10,11,33,53}$

Our institute used intraoperative MVD sonography and ICG videoangiography before adding the use of intraoperative EP monitoring, and recently we adopted the mobile CT scan. Each intraoperative monitoring method has a different spectrum of detection, continuity, monitored features, and invasiveness. Therefore, the use of multiple monitoring techniques provides greater coverage and detection of surgically induced complications, leading to safer surgical treatment of UIAs. ${ }^{42,43}$ In transcranial EP monitoring, meticulous interpretation of each event is crucial. Thus, a baseline MEP/SEP recording is performed the day before surgery to provide information on the preoperative elec- 
TABLE 4. False-negative cases

\begin{tabular}{|c|c|c|c|c|c|c|c|c|c|c|c|c|c|c|}
\hline \multirow[b]{2}{*}{$\begin{array}{l}\text { Case } \\
\text { No. }\end{array}$} & \multirow{2}{*}{$\begin{array}{l}\text { Age } \\
(y r s) \\
\text { Sex }\end{array}$} & \multicolumn{2}{|c|}{$\begin{array}{c}\text { Aneurysm } \\
\text { Characteristics }\end{array}$} & \multirow[b]{2}{*}{$\begin{array}{l}\text { Muscle } \\
\text { Relaxant }\end{array}$} & \multicolumn{2}{|c|}{ MEP Cx } & \multicolumn{2}{|c|}{ SEP CX } & \multirow[b]{2}{*}{ Periop Complications } & \multirow{2}{*}{$\begin{array}{l}\text { Lesion } \\
\text { Size } \\
(\mathrm{cm})^{*}\end{array}$} & \multicolumn{2}{|c|}{ Motor Grade } & \multirow[b]{2}{*}{ GOS† } & \multirow[b]{2}{*}{$\mathrm{mRS} \ddagger$} \\
\hline & & Location & $\begin{array}{l}\text { Size } \\
(\mathrm{mm})\end{array}$ & & Persist & Any & Persist & Any & & & $\begin{array}{l}\text { POD } \\
0\end{array}$ & $\begin{array}{l}1 \mathrm{Mo} \\
\text { Postop }\end{array}$ & & \\
\hline 1 & $46, F$ & Paraclinoid & 5.6 & Contin & - & - & - & - & Postop temp lobe ICH, SAH & 2.5 & 4 & 5 & 5 & 0 \\
\hline 2 & $75, \mathrm{~F}$ & MCA & 13.2 & Contin & - & - & - & - & Acute infarction in It MCA terr & 1.3 & 3 & 4 & 5 & 0 \\
\hline \multirow[t]{3}{*}{3} & $56, \mathrm{~F}$ & MCA & 3 & Contin & - & - & - & - & $\begin{array}{l}\text { Acute infarction in It lat LSA } \\
\text { terr }\end{array}$ & 3.8 & 2 & 5 & 5 & 0 \\
\hline & & AChA & 2 & & & & & & & & & & & \\
\hline & & ICA bifurc & 3 & & & & & & & & & & & \\
\hline 4 & $72, \mathrm{~F}$ & MCA & 7.1 & Contin & - & - & - & - & $\begin{array}{l}\text { Appearance of several DWI } \\
\text { high-signal cortical lesions } \\
\text { in It paracentral lobule }\end{array}$ & 0.6 & 4 & 5 & 5 & 0 \\
\hline 5 & $69, \mathrm{~F}$ & PCoA & 5 & Contin & - & - & - & - & Rt AChA terr infarction & 0.8 & 4 & 5 & 5 & 0 \\
\hline 6 & $49, \mathrm{M}$ & MCA & 4.6 & Contin & - & - & - & - & $\begin{array}{l}\text { Recent infarction w/ hemor- } \\
\text { rhage in rt basal ganglia }\end{array}$ & 4.7 & 4 & 4 & 4 & 1 \\
\hline 7 & $71, \mathrm{~F}$ & AchA & 4 & Contin & - & - & - & - & $\begin{array}{l}\text { Focal acute infarction, It } \\
\text { anteromedial thalamus }\end{array}$ & 0.9 & 4 & 5 & 5 & 0 \\
\hline \multirow[t]{3}{*}{8} & $60, \mathrm{~F}$ & $\mathrm{ACoA}$ & 18 & Contin & - & - & - & - & $\begin{array}{l}\text { Ischemic Cx in rt ACA terr } \rightarrow \\
\text { confusion }\end{array}$ & 0.9 & 2 & 5 & 4 & 3 \\
\hline & & MCA & 2.9 & & & & & & & & & & & \\
\hline & & AchA & 2.8 & & & & & & & & & & & \\
\hline
\end{tabular}

$\mathrm{DWI}=$ diffusion-weighted imaging; $\mathrm{LSA}=$ lenticulostriate artery; temp = temporal; terr = territory.

* Maximum diameter.

$\dagger$ GOS score at discharge.

$\ddagger$ mRS score at 6 months' follow-up.

trophysiological status. These results can be used to avoid false positives when abnormal EP results are discussed intraoperatively. Additionally, MVD sonography and ICG videoangiography can aid in determining whether to continue the surgical process in such cases.

Theoretically, intraoperative MEP and SEP monitoring can detect neurophysiological changes in the motor cortex/ corticospinal and spinothalamic pathways, respectively, before an actual brain infarction, as inhibition of synaptic transmission occurs before irreversible damage..$^{14,17,19,23,44,46}$ However, observation and evaluation of sensory function changes is more difficult than observation and evaluation of motor function changes. Thus, clinicians usually focus on MEP monitoring results and consider SEP results as supplemental information that can provide greater coverage of brain lesions with the advantage of continuous monitoring.

False-negative cases in intraoperative transcranial EP monitoring can be explained by different mechanisms. First, direct stimulation of deeper structures within the subcortical motor pathway can bypass the ischemic lesion and lead to false-negative results. . $^{80,38,49}$ Previous studies have reported that even corticospinal axons as deep as the pyramidal decussation can be activated via the foramen magnum at high stimulation intensities. ${ }^{8,49}$ To avoid this phenomenon, some authors suggest direct cortical stimulation via placement of a subdural strip or grid electrode instead of transcranial stimulation. ${ }^{58,61,63}$ However, direct cortical stimulation also has limitations, such as an increased chance of hemorrhage and brain injury and difficulty in detecting EPs of lower extremities. ${ }^{38,61}$ Furthermore, reports show that transcranial and direct electrical stimulation do not differ in their ability to detect ischemic lesions in the motor pathway. ${ }^{62}$ Therefore, our institute prefers transcranial EP monitoring rather than direct cortical stimulation because the conventional pterional approach does not typi-

TABLE 5. Sensitivity, specificity, PPV, and NPV

\begin{tabular}{|c|c|c|c|c|c|}
\hline \multirow[b]{2}{*}{ Characteristic } & \multicolumn{2}{|c|}{ SEP CX $(95 \% \mathrm{Cl})$} & \multicolumn{2}{|c|}{ MEP Cx $(95 \%$ Cl) } & \multirow{2}{*}{$\begin{array}{l}\text { Overall EP Cx } \\
\qquad(95 \% \mathrm{Cl})\end{array}$} \\
\hline & Persist & Any & Persist & Any & \\
\hline Sensitivity & $0.000(0.000-0.287)$ & $0.000(0.000-0334)$ & $0.000(0.000-0.315)$ & $0.000(0.000-0.332)$ & $0.100(0.005-0.454)$ \\
\hline Specificity & $0.995(0.995-0.997)$ & $0.973(0.973-0.975)$ & $0.990(0.990-0.992)$ & $0.976(0.976-0.978)$ & $0.941(0.940-0.943)$ \\
\hline PPV & $0.000(0.000-0.359)$ & $0.000(0.000-0.081)$ & $0.000(0.000-0.210)$ & $0.000(0.000-0.092)$ & $0.011(0.001-0.050)$ \\
\hline NPV & $0.993(0.993-0.995)$ & $0.993(0.993-0.995)$ & $0.993(0.993-0.995)$ & $0.993(0.993-0.995)$ & $0.994(0.993-0.996)$ \\
\hline
\end{tabular}



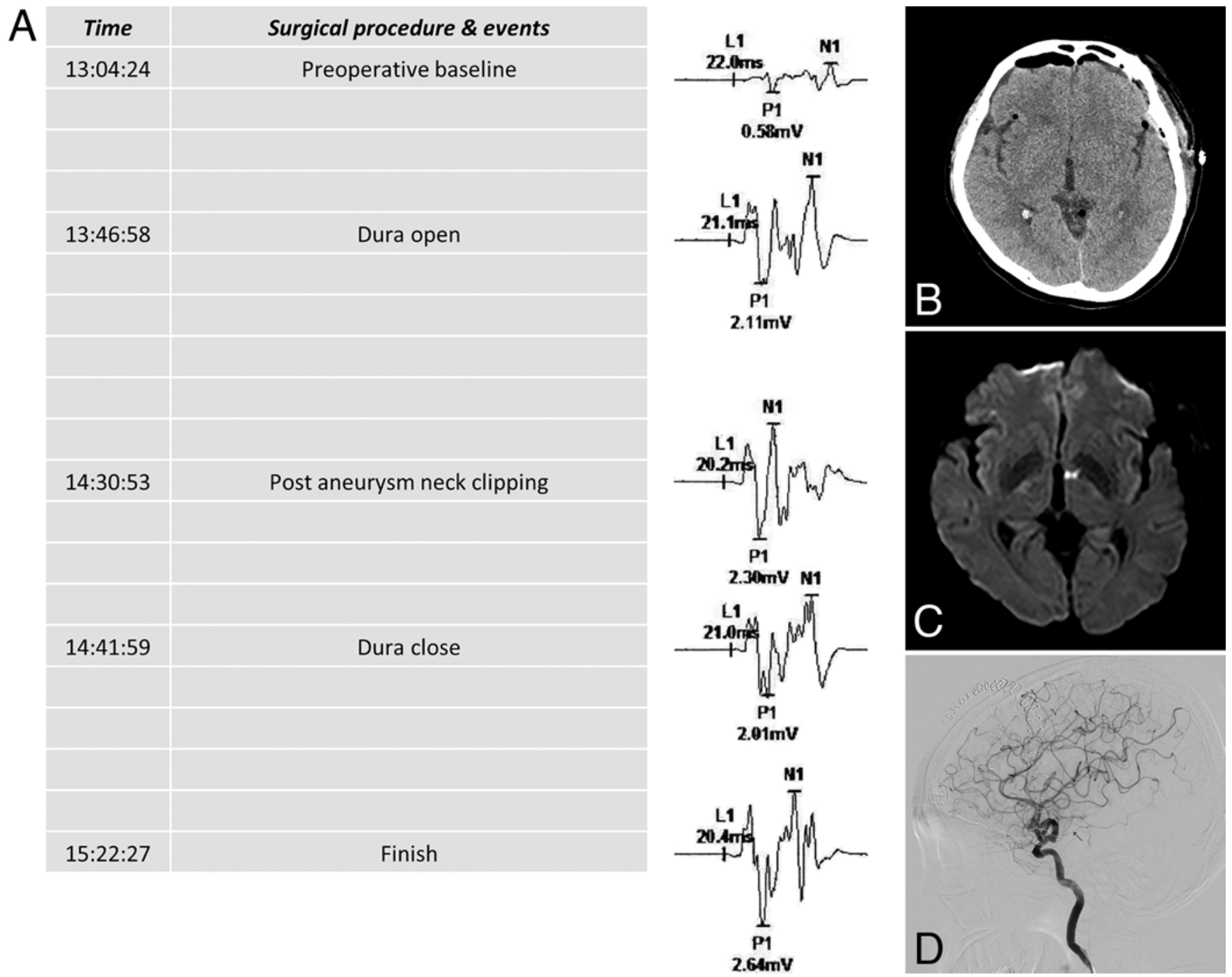

FIG. 1. This 71-year-old woman had a 4-mm aneurysm at the origin of AChA (case 7 in Table 4). ICG videoangiography and MVD sonography confirmed the patency of the internal carotid artery and AChA. There was no significant EP change during the operation (A); however, the patient showed grade 4 motor deficits in the right upper and lower extremities. Brain CT scans performed immediately after surgery and 1 day postoperatively revealed nothing abnormal (B), but the patient's motor weakness did not resolve. Thus, diffusion-weighted imaging was performed 3 days postoperatively and revealed a focal acute infarction at the left anteromedial thalamus (C). However, the AChA was shown to be patent by postoperative DSA immediately following the diffusionweighted imaging study (D).

cally expose the motor cortex, and this would force blind insertion of the strip, increasing the chance of brain cortex injury. Additionally, at our institute a preoperative EP evaluation is performed the day before surgery to refine the stimulation intensity and make it as low as possible. Second, motor weakness can occur from a lesion that is not located in the corticospinal pathway. The corticospinal pathway descends through the corona radiata to the internal capsule, cerebral peduncle, basis pontis, and then the medullary pyramids before finally reaching the spinal cord. Infarction in these regions will cause a significant EP change, resulting in hemiplegia. A recent study reported that an ischemic lesion in the premotor area could lead to motor deficits without any significant EP changes. ${ }^{58}$ Motor weakness caused by an infarction in the supplemental motor areas and pathways can be hard to distinguish from that caused by pure motor hemiplegia through direct involvement of the motor pathway.

Another possible cause of false-negative results is motor weakness without a neurophysiological change in the axons of the corticospinal pathway. Energy depletion because of the ischemic state causes changes in the EP results..$^{14,17,23}$ In contrast, an intracranial mass, which causes mechanical compression of the motor pathway due to ICH or subdural hemorrhage (SDH), might result in motor weakness. We could not find evidence of a relationship between mechanical compression and EP changes in human studies. However, in animal studies, it was observed that a large acute SDH could cause a decrease in the amplitude of SEP, whereas a small acute SDH causes only a temporary SEP change. ${ }^{65}$ This phenomenon indirectly suggests that a small hemorrhage that does not affect a 
A

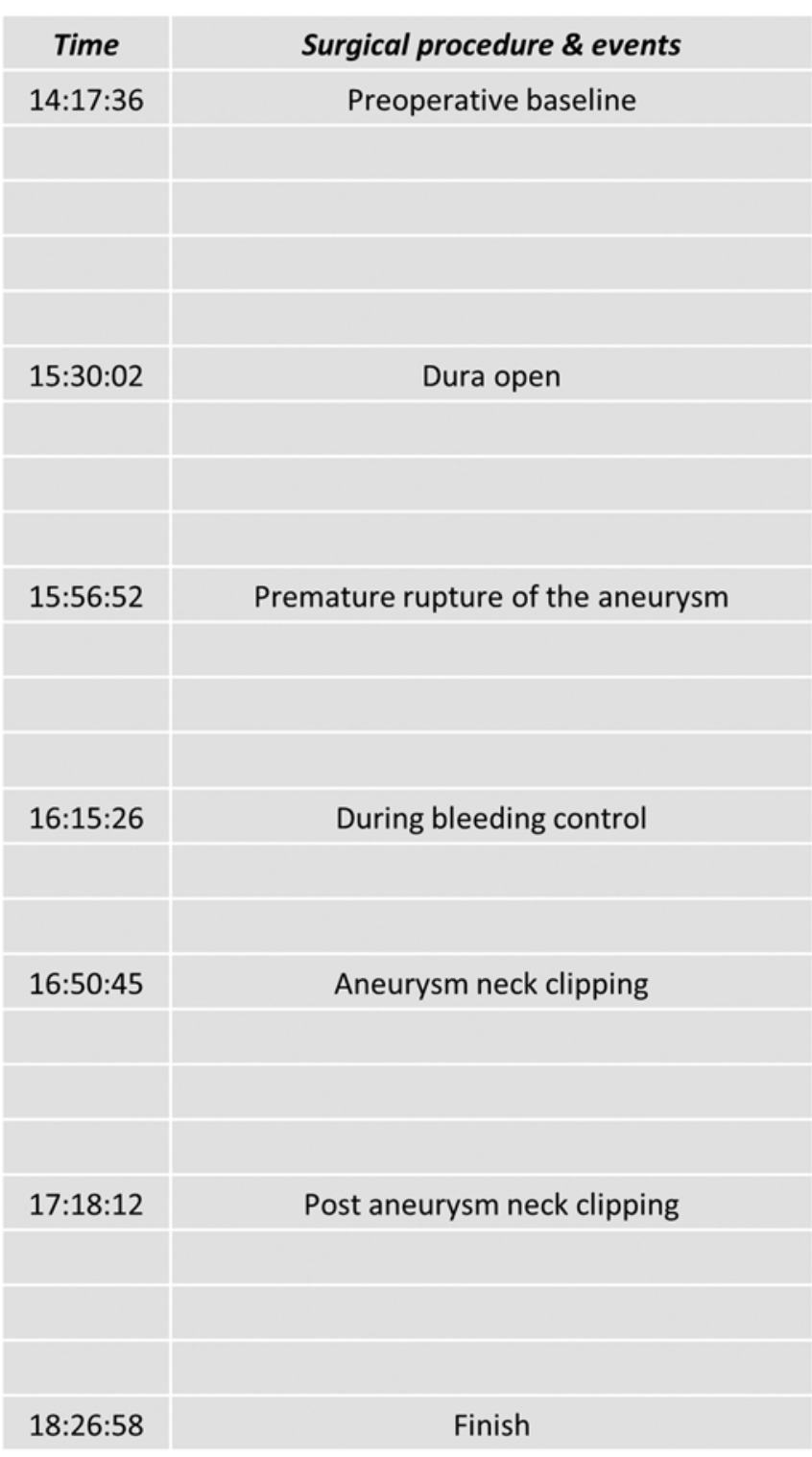

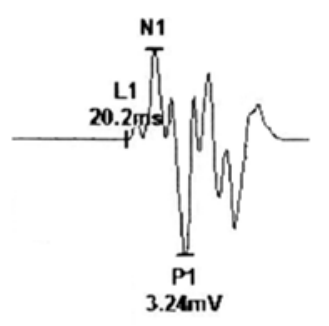
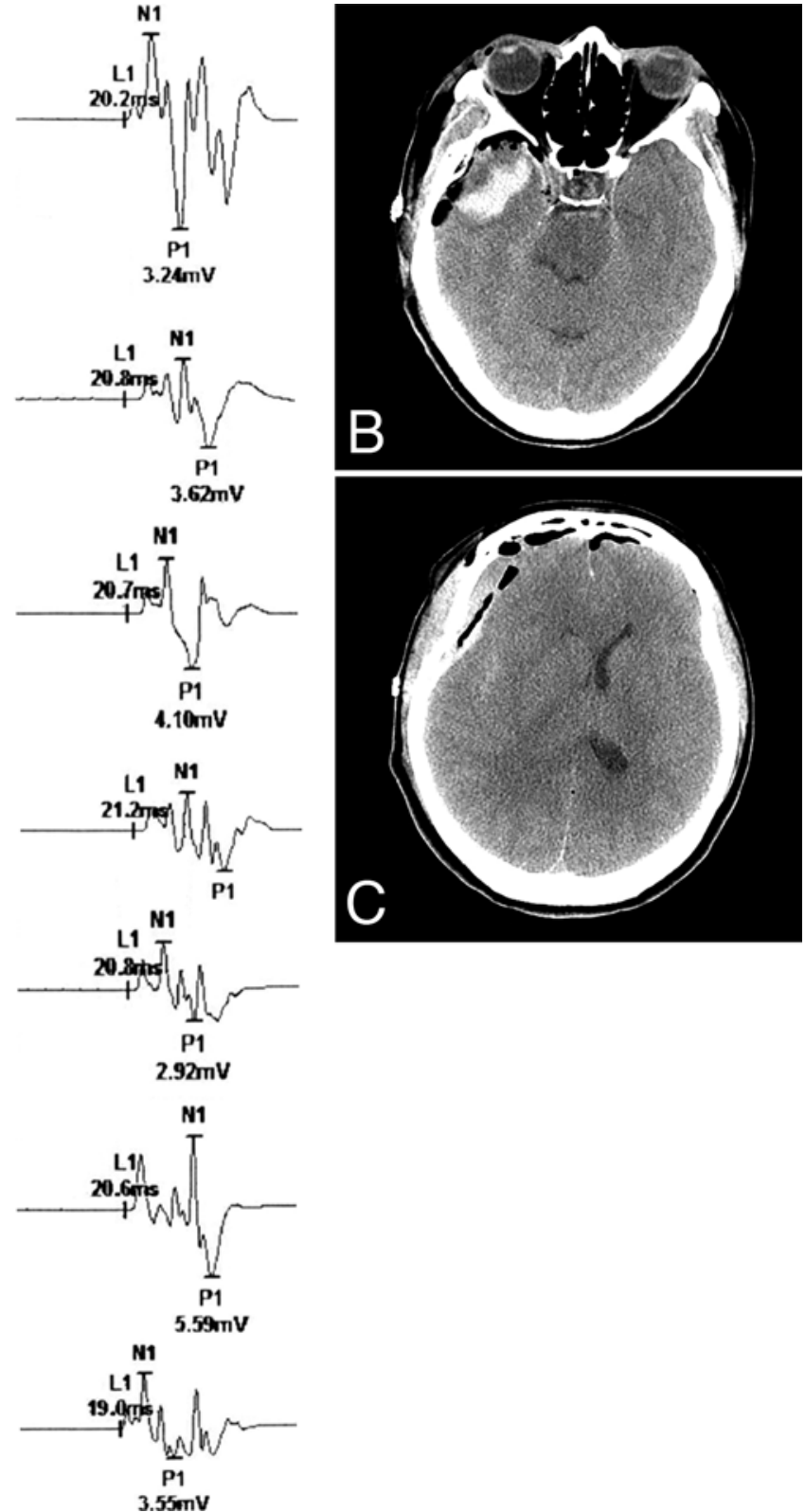

FIG. 2. This 46-year-old woman had a 5.6-mm paraclinoid aneurysm (case 1 in Table 4). During the intradural removal of the anterior clinoid process, the surgical high-speed drill injured the medial temporal lobe. The paraclinoid aneurysm was clipped after the bleeding was brought under control. ICG videoangiography and MVD sonography confirmed the patency of the internal carotid artery and its branches, and there were no significant EP changes observed during surgery (A). However, the patient had grade 4 motor deficits in the left upper and lower extremities with ipsilateral ptosis. Postoperative brain $\mathrm{CT}$ revealed an ICH in the temporal lobe and an SAH with midline shift toward the contralateral side (B and C).

decrease in the cerebral blood flow could result in motor weakness with preserved neurophysiological function. We encountered a false-negative case with postoperative ICH and SAH without any EP change (case 1 in Table 4; Fig. 2).

False-positive transcranial EP monitoring results are usually due to the gap between the brain cortex and the calvaria. Brain shifting caused by excess CSF drainage typically causes this phenomenon. Unfortunately, it is almost impossible to determine whether the positive EP change is true or false, and making a wrong decision could result in a harmful outcome for the patient. Therefore, once there is significant EP change, the surgeon should consider adjusting or repositioning the aneurysm clip. Analyses using additional methods, such as MVD sonography, intraoperative blood flow measurement, and ICG videoangiography, should also be considered. In addition, replacement of CSF with normal saline and slightly rotating the head toward the neutral position can normalize EP results. Despite these methods, there were 15 false-positive cases during the study period. Significant EP changes were considered to be false positives after consolidating results from MVD 

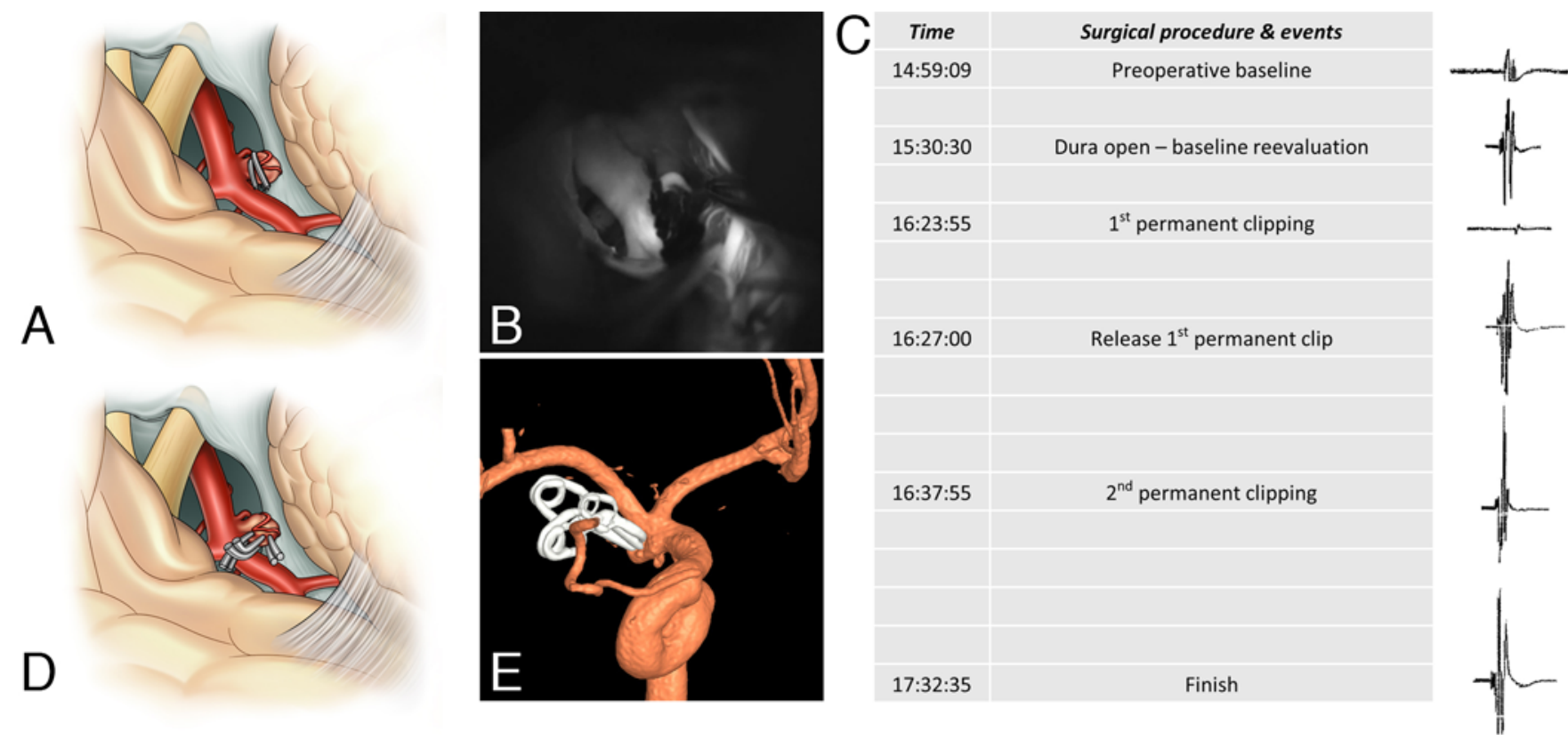

FIG. 3. This 72-year-old woman had a 7.4-mm right AChA aneurysm at the point of branching from the right distal internal carotid artery. Two standard clips were applied, leaving enough space from the AChA, which was severely stenotic. However, one of the aneurysm clips had to be placed over a perforating vessel, as the perforator was severely adhered to the aneurysm dome $(\mathbf{A})$. ICG videoangiography confirmed the patent blood flow of AChA (B). However, the EP amplitude dropped more than $50 \%$, but the EP results soon normalized after release of the previously applied aneurysm clips (C). Thus, the aneurysm was partially clipped to preserve the small perforator ( $D$ and $E$ ). The remnant aneurysm sac was secured with endovascular coiling. Panels $A$ and $D$ copyright Asan Medical Center. Published with permission. Figure is available in color online only.

sonography and ICG videoangiography and comparing them with the anatomical relation of the vasculature to the aneurysm.

As mentioned above, EP changes occur before persistent ischemic brain damage. Thus, persistent and recovered EP changes could have different clinical meanings. MEP and SEP each have different coverage of brain lesions. Thus, the sensitivity, specificity, PPV, and NPV were calculated for each persistent MEP change, persistent SEP change, any MEP change, any SEP change, and overall EP change. We also determined which is the best method to predict ischemic change; however, no significant differences were found by logistic regression analysis. All results tended to show high specificity and NPV with low sensitivity and PPV.

Alert criteria and interpretation of false-positive and false-negative results differ from one study to another. ${ }^{13,22,}$ 26,37,57,58,63,64,68,69 For example, Takebayashi et al. used the complete loss of MEP amplitude as the alert criterion, whereas Szelényi et al. included a case in which the patient experienced delayed motor weakness as a false-negative case. ${ }^{63,64}$ Hence, simple comparison of EP results from each report could lead to misinterpretation. To minimize this issue, we categorized the false-positive and false-negative criteria of previous studies and matched our definitions as closely as possible, depending on the existence of persistent MEP decline and immediate postoperative motor deficits. If there was no description of immediate neurological examinations in other previous studies, operative-day motor weakness was considered an immediate postoperative motor deficit. Thus, despite their different alert criteria, all previous studies resulted in low sensitivity (0.000-0.500) and high specificity (0.990-1.000) with relatively few false-positive $(0 \%-0.99 \%)$ and false-negative $(0 \%-40 \%)$ cases (Table 6).

Furthermore, to the best of our knowledge, the current study is the largest survey of EP monitoring to date. Therefore, we had a greater chance of encountering false positives and false negatives. Nonetheless, the incidence of false-positive or false-negative cases was less than $1 \%$ in our study. We believe this was the result of 3 key features. First, preoperative EP monitoring provided information about the initial condition of patients for improving the accuracy of our interpretation of EP monitoring results. Second, rigorous EP monitoring techniques ensured highquality EP results. Well-orchestrated total intravenous anesthesia with minimal use of NMB and a carefully refined minimal stimulation intensity (which was lower than in other studies) reduced the chances of a bypass in electrical stimulation (electrical stimulation bypassing the ischemic lesion, which can result in a false negative). Third, communications between the surgeon, anesthesiologist, and neurophysiologist were always open for discussion to gather all opinions and information related to any patient events. These features made EP monitoring an excellent and reliable tool as a surrogate indicator in possible ischemic neurological deficits.

\section{Limitations}

Although the present study involved a large group of cases, there were some limitations. Because we used ret- 


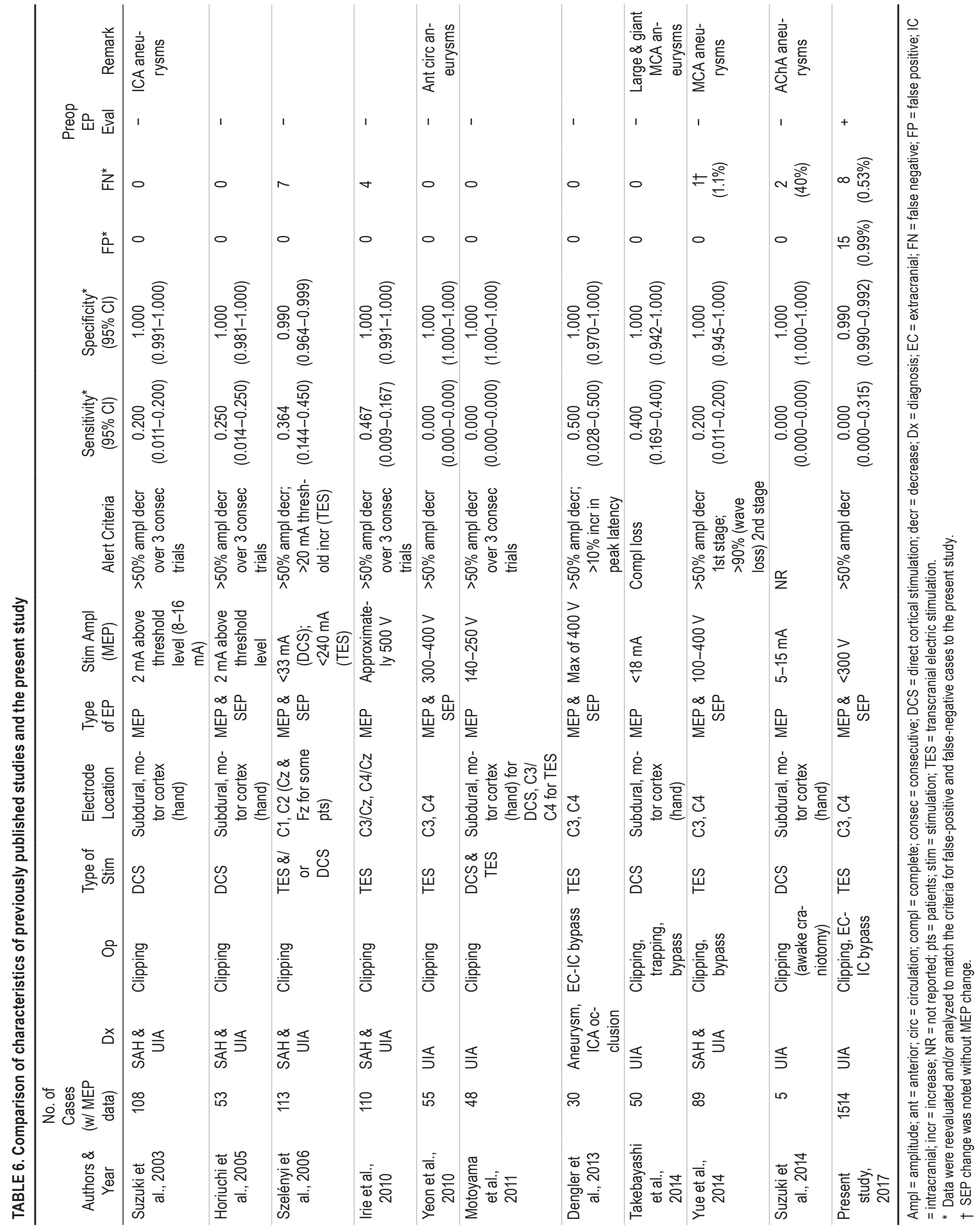


rospective data, we could not unify the use of NMB in an anesthetic regimen, which could potentially alter EP results. ${ }^{30}$ Moreover, although we could roughly categorize patients into subgroups, the efficacy of NMB could not be controlled due to multiple variables, such as body weight, operation time, and injection rate. Thus, the use of NMB was only analyzed as additional information for each patient. Second, we could only identify some of the causes of EP changes from EP records, such as temporary clipping of the proximal parent artery or permanent clipping. In addition, some records did not include a description of the event, and there was not an adequate description of how EP results were recovered. Hence, statistical analysis of the cause of EP events was not included.

The time gap between the end of EP monitoring and the start of immediate postoperative neurological examination could also be a limitation. Due to imperfections in the medical records, we could not evaluate the mean time from the end of the monitoring to the immediate postoperative neurological examination. From our experience, it takes 30-60 minutes for patients to wake from anesthesia, and there is a chance of a change in the environment of an intracranial lesion during this period. It is possible that awake surgery could improve or eliminate this issue, but ethical and technical concerns related to this type of surgery would need to be addressed, and this would not be an efficient common surgical protocol. ${ }^{58}$

Due to the low incidence of false positives, false negatives, and overall complications, and the size of the population differences between the patient groups, we were unable to demonstrate any statistical significance for independent risk factors associated with false positives, false negatives, or complications. Moreover, the clinically meaningful definition of false positive and false negative differed slightly from those used for statistical analysis. The most challenging part of the current study was defining criteria for false positives and false negatives, as there were various factors to consider, making their definition difficult. Thus, PPV and PNV were calculated for EP results; however, these analyses do not reflect the exact same patient groups as false positives and false negatives. Nevertheless, our study is based on one of the largest reported series of patients who underwent surgical treatment of UIAs with intraoperative EP monitoring, and it included analysis of the incidence of false-positive and false-negative cases.

Finally, there are limitations with transcranial EP monitoring itself. Transcranial EP monitoring can detect neurophysiological changes, but it does not quantify neural damage. Therefore, the finding of a $50 \%$ decrease in the amplitude of EP results does not always indicate neurological damage. In our case series, the cerebral infarct lesions in patients with false-negative EP results were focal. These did not result in complete paralysis, and most affected patients recovered within 1 month. Lack of detection by EP monitoring is possible because of partial neural injury or a bypass of stimulation due to a relatively small lesion.

\section{Conclusions}

In the present study, intraoperative EP monitoring proved to be an effective tool for detecting impending cerebral ischemia during aneurysm surgery; it had high specificity and NPV. Although the incidence of false-positive and false-negative cases is low, their existence may be a pitfall during aneurysm surgery. However, a meticulously designed protocol helps make EP monitoring an excellent surrogate indicator in cases with a possibility of ischemic neurological deficits.

\section{References}

1. Alshekhlee A, Mehta S, Edgell RC, Vora N, Feen E, Mohammadi A, et al: Hospital mortality and complications of electively clipped or coiled unruptured intracranial aneurysm. Stroke 41:1471-1476, 2010

2. Bacigaluppi S, Fontanella M, Manninen P, Ducati A, Tredici G, Gentili F: Monitoring techniques for prevention of procedure-related ischemic damage in aneurysm surgery. World Neurosurg 78:276-288, 2012

3. Barker FG II, Amin-Hanjani S, Butler WE, Ogilvy CS, Carter BS: In-hospital mortality and morbidity after surgical treatment of unruptured intracranial aneurysms in the United States, 1996-2000: the effect of hospital and surgeon volume. Neurosurgery 52:995-1009, 2003

4. Bekelis K, Missios S, MacKenzie TA, Desai A, Fischer A, Labropoulos N, et al: Predicting inpatient complications from cerebral aneurysm clipping: the Nationwide Inpatient Sample 2005-2009. J Neurosurg 120:591-598, 2014

5. Brilstra EH, Rinkel GJ, van der Graaf Y, Sluzewski M, Groen RJ, Lo RT, et al: Quality of life after treatment of unruptured intracranial aneurysms by neurosurgical clipping or by embolisation with coils. A prospective, observational study. Cerebrovasc Dis 17:44-52, 2004

6. Brinjikji W, Rabinstein AA, Nasr DM, Lanzino G, Kallmes DF, Cloft HJ: Better outcomes with treatment by coiling relative to clipping of unruptured intracranial aneurysms in the United States, 2001-2008. AJNR Am J Neuroradiol 32:1071-1075, 2011

7. Bruneau M, Amin-Hanjani S, Koroknay-Pal P, Bijlenga P, Jahromi BR, Lehto H, et al: Surgical clipping of very small unruptured intracranial aneurysms: A multicenter international study. Neurosurgery 78:47-52, 2016

8. Burke D, Hicks RG, Stephen JP: Corticospinal volleys evoked by anodal and cathodal stimulation of the human motor cortex. J Physiol 425:283-299, 1990

9. Cho MS, Kim MS, Chang CH, Kim SW, Kim SH, Choi BY: Analysis of clip-induced ischemic complication of anterior choroidal artery aneurysms. J Korean Neurosurg Soc 43:131-134, 2008

10. Davis SF, Altstadt T, Flores R, Kaye A, Oremus G: Report of seizure following intraoperative monitoring of transcranial motor evoked potentials. Ochsner J 13:558-560, 2013

11. Davis SF, Kalarickal P, Strickland T: A report of two cases of lip and tongue bite injury associated with transcranial motor evoked potentials. Am J Electroneurodiagn Technol 50:313-320, 2010

12. Deletis V: What does intraoperative monitoring of motor evoked potentials bring to the neurosurgeon? Acta Neurochir (Wien) 147:1015-1017, 2005

13. Dengler J, Cabraja M, Faust K, Picht T, Kombos T, Vajkoczy P: Intraoperative neurophysiological monitoring of extracranial-intracranial by pass procedures. J Neurosurg 119:207-214, 2013

14. Dirnagl U, Iadecola C, Moskowitz MA: Pathobiology of ischaemic stroke: an integrated view. Trends Neurosci 22:391397,1999 
15. Ducati A, Landi A, Cenzato M, Fava E, Rampini P, Giovanelli M, et al: Monitoring of brain function by means of evoked potentials in cerebral aneurysm surgery. Acta Neurochir Suppl (Wien) 42:8-13, 1988

16. Fay MP: Confidence intervals that match Fisher's exact or Blaker's exact tests. Biostatistics 11:373-374, 2010

17. Florence G, Guerit JM, Gueguen B: Electroencephalography (EEG) and somatosensory evoked potentials (SEP) to prevent cerebral ischaemia in the operating room. Neurophysiol Clin 34:17-32, 2004

18. Gerlach R, Beck J, Setzer M, Vatter H, Berkefeld J, Du Mesnil de Rochemont R, et al: Treatment related morbidity of unruptured intracranial aneurysms: results of a prospective single centre series with an interdisciplinary approach over a 6 year period (1999-2005). J Neurol Neurosurg Psychiatry 78:864-871, 2007

19. Grossauer S, Koeck K, Kraschl J, Olipitz O, Hausegger KA, Vince GH: Detection of cerebral vasospasm following aneurysmal subarachnoid hemorrhage using motor evoked potentials. Neurosurgery 78:265-273, 2016

20. Guo L, Gelb AW: The use of motor evoked potential monitoring during cerebral aneurysm surgery to predict pure motor deficits due to subcortical ischemia. Clin Neurophysiol 122:648-655, 2011

21. Holdefer RN, MacDonald DB, Guo L, Skinner SA: An evaluation of motor evoked potential surrogate endpoints during intracranial vascular procedures. Clin Neurophysiol 127:1717-1725, 2016

22. Horiuchi K, Suzuki K, Sasaki T, Matsumoto M, Sakuma J, Konno Y, et al: Intraoperative monitoring of blood flow insufficiency during surgery of middle cerebral artery aneurysms. J Neurosurg 103:275-283, 2005

23. Hossmann KA: Pathophysiology and therapy of experimental stroke. Cell Mol Neurobiol 26:1057-1083, 2006

24. Hyun SJ, Rhim SC: Combined motor and somatosensory evoked potential monitoring for intramedullary spinal cord tumor surgery: correlation of clinical and neurophysiological data in 17 consecutive procedures. Br J Neurosurg 23:393400, 2009

25. Ichikawa T, Suzuki K, Sasaki T, Matsumoto M, Sakuma J, Oinuma M, et al: Utility and the limit of motor evoked potential monitoring for preventing complications in surgery for cerebral arteriovenous malformation. Neurosurgery 67 (3 Suppl Operative):ons222-ons228, 2010

26. Irie T, Yoshitani K, Ohnishi Y, Shinzawa M, Miura N, Kusaka Y, et al: The efficacy of motor-evoked potentials on cerebral aneurysm surgery and new-onset postoperative motor deficits. J Neurosurg Anesthesiol 22:247-251, 2010

27. Jalbert JJ, Isaacs AJ, Kamel H, Sedrakyan A: Clipping and coiling of unruptured intracranial aneurysms among medicare beneficiaries, 2000 to 2010. Stroke 46:2452-2457, 2015

28. Jennett B, Bond M: Assessment of outcome after severe brain damage. Lancet 1:480-484, 1975

29. Kaga A, Fujiki M, Hori S, Nakano T, Isono M: Motor evoked potentials following transcranial magnetic stimulation after middle cerebral artery and/or basilar artery occlusions in rats. J Clin Neurosci 10:470-475, 2003

30. Kim WH, Lee JJ, Lee SM, Park MN, Park SK, Seo DW, et al: Comparison of motor-evoked potentials monitoring in response to transcranial electrical stimulation in subjects undergoing neurosurgery with partial vs no neuromuscular block. Br J Anaesth 110:567-576, 2013

31. King JT Jr, Berlin JA, Flamm ES: Morbidity and mortality from elective surgery for asymptomatic, unruptured, intracranial aneurysms: a meta-analysis. J Neurosurg 81:837-842, 1994

32. Krisht AF, Gomez J, Partington S: Outcome of surgical clipping of unruptured aneurysms as it compares with a 10-year nonclipping survival period. Neurosurgery 58:207-216, 006
33. MacDonald DB: Safety of intraoperative transcranial electrical stimulation motor evoked potential monitoring. J Clin Neurophysiol 19:416-429, 2002

34. Macdonald RL, Wallace MC, Kestle JR: Role of angiography following aneurysm surgery. J Neurosurg 79:826-832, 1993

35. Mahaney KB, Brown RD Jr, Meissner I, Piepgras DG, Huston J III, Zhang J, et al: Age-related differences in unruptured intracranial aneurysms: 1-year outcomes. J Neurosurg 121:1024-1038, 2014

36. Moroi J, Hadeishi H, Suzuki A, Yasui N: Morbidity and mortality from surgical treatment of unruptured cerebral aneurysms at Research Institute for Brain and Blood VesselsAkita. Neurosurgery 56:224-231, 2005

37. Motoyama Y, Kawaguchi M, Yamada S, Nakagawa I, Nishimura F, Hironaka Y, et al: Evaluation of combined use of transcranial and direct cortical motor evoked potential monitoring during unruptured aneurysm surgery. Neurol Med Chir (Tokyo) 51:15-22, 2011

38. Neuloh G, Schramm J: Are there false-negative results of motor evoked potential monitoring in brain surgery? Cent Eur Neurosurg 70:171-175, 2009

39. Neuloh G, Schramm J: Monitoring of motor evoked potentials compared with somatosensory evoked potentials and microvascular Doppler ultrasonography in cerebral aneurysm surgery. J Neurosurg 100:389-399, 2004

40. Niskanen M, Koivisto T, Rinne J, Ronkainen A, Pirskanen $\mathrm{S}$, Saari T, et al: Complications and postoperative care in patients undergoing treatment for unruptured intracranial aneurysms. J Neurosurg Anesthesiol 17:100-105, 2005

41. Ohno K, Arai T, Isotani E, Nariai T, Hirakawa K: Ischaemic complication following obliteration of unruptured cerebral aneurysms with atherosclerotic or calcified neck. Acta Neurochir (Wien) 141:699-706, 1999

42. Park W, Ahn JS, Lee SH, Park JC, Kwun BD: Results of reexploration because of compromised distal blood flow after clipping unruptured intracranial aneurysms. Acta Neurochir (Wien) 157:1015-1024, 2015

43. Park W, Ahn JS, Park JC, Kwon DH, Kwun BD, Kim CJ: Re-exploration of the craniotomy after surgical treatment of unruptured intracranial aneurysms. Acta Neurochir (Wien) 156:869-877, 2014

44. Quiñones-Hinojosa A, Alam M, Lyon R, Yingling CD, Lawton MT: Transcranial motor evoked potentials during basilar artery aneurysm surgery: technique application for 30 consecutive patients. Neurosurgery 54:916-924, 2004

45. Raabe A, Nakaji P, Beck J, Kim LJ, Hsu FP, Kamerman JD, et al: Prospective evaluation of surgical microscopeintegrated intraoperative near-infrared indocyanine green videoangiography during aneurysm surgery. J Neurosurg 103:982-989, 2005

46. Raabe A, Seidel K: Prevention of ischemic complications during aneurysm surgery. J Neurosurg Sci 60:95-103, 2016

47. Raaymakers TW, Rinkel GJ, Limburg M, Algra A: Mortality and morbidity of surgery for unruptured intracranial aneurysms: a meta-analysis. Stroke 29:1531-1538, 1998

48. Rosen $\varnothing \mathbf{r n} \mathrm{J}$ : The risk of ischaemic brain damage during the use of self-retaining brain retractors. Acta Neurol Scand Suppl 120:1-30, 1989

49. Rothwell J, Burke D, Hicks R, Stephen J, Woodforth I, Crawford M: Transcranial electrical stimulation of the motor cortex in man: further evidence for the site of activation. $\mathbf{J}$ Physiol 481:243-250, 1994

50. Sakuma J, Suzuki K, Sasaki T, Matsumoto M, Oinuma M, Kawakami M, et al: Monitoring and preventing blood flow insufficiency due to clip rotation after the treatment of internal carotid artery aneurysms. J Neurosurg 100:960-962, 2004

51. Sasaki T, Kodama N, Matsumoto M, Suzuki K, Konno Y, Sakuma J, et al: Blood flow disturbance in perforating arteries 
attributable to aneurysm surgery. J Neurosurg 107:60-67, 2007

52. Schichor C, Rachinger W, Morhard D, Zausinger S, Heigl TJ, Reiser M, et al: Intraoperative computed tomography angiography with computed tomography perfusion imaging in vascular neurosurgery: feasibility of a new concept. J Neurosurg 112:722-728, 2010

53. Schwartz DM, Sestokas AK, Dormans JP, Vaccaro AR, Hilibrand AS, Flynn JM, et al: Transcranial electric motor evoked potential monitoring during spine surgery: is it safe? Spine (Phila Pa 1976) 36:1046-1049, 2011

54. Seifert V, Gerlach R, Raabe A, Güresir E, Beck J, Szelényi A, et al: The interdisciplinary treatment of unruptured intracranial aneurysms. Dtsch Arztebl Int 105:449-456, 2008

55. Sulter G, Steen C, De Keyser J: Use of the Barthel index and modified Rankin scale in acute stroke trials. Stroke 30:15381541, 1999

56. Suzuki H, Fujita K, Ehara K, Tamaki N: Anterior choroidal artery syndrome after surgery for internal carotid artery aneurysms. Neurosurgery 31:132-136, 1992

57. Suzuki K, Kodama N, Sasaki T, Matsumoto M, Konno Y, Sakuma J, et al: Intraoperative monitoring of blood flow insufficiency in the anterior choroidal artery during aneurysm surgery. J Neurosurg 98:507-514, 2003

58. Suzuki K, Mikami T, Sugino T, Wanibuchi M, Miyamoto S, Hashimoto N, et al: Discrepancy between voluntary movement and motor-evoked potentials in evaluation of motor function during clipping of anterior circulation aneurysms. World Neurosurg 82:e739-e745, 2014

59. Szelényi A, Beck J, Strametz R, Blasel S, Oszvald A, Raabe $A$, et al: Is the surgical repair of unruptured atherosclerotic aneurysms at a higher risk of intraoperative ischemia? Clin Neurol Neurosurg 113:129-135, 2011

60. Szelényi A, Bueno de Camargo A, Flamm E, Deletis V: Neurophysiological criteria for intraoperative prediction of pure motor hemiplegia during aneurysm surgery. Case report. J Neurosurg 99:575-578, 2003

61. Szelényi A, Kothbauer K, de Camargo AB, Langer D, Flamm ES, Deletis V: Motor evoked potential monitoring during cerebral aneurysm surgery: technical aspects and comparison of transcranial and direct cortical stimulation. Neurosurgery 57 (4 Suppl):331-338, 2005

62. Szelényi A, Langer D, Beck J, Raabe A, Flamm ES, Seifert $\mathrm{V}$, et al: Transcranial and direct cortical stimulation for motor evoked potential monitoring in intracerebral aneurysm surgery. Neurophysiol Clin 37:391-398, 2007

63. Szelényi A, Langer D, Kothbauer K, De Camargo AB, Flamm ES, Deletis V: Monitoring of muscle motor evoked potentials during cerebral aneurysm surgery: intraoperative changes and postoperative outcome. J Neurosurg 105:675681,2006

64. Takebayashi S, Kamiyama H, Takizawa K, Kobayashi T, Saitoh N: The significance of intraoperative monitoring of muscle motor evoked potentials during unruptured large and giant cerebral aneurysm surgery. Neurol Med Chir (Tokyo) 54:180-188, 2014

65. Timaru-Kast R, Meissner A, Heimann A, Hoelper B, Kempski O, Alessandri B: Acute subdural hematoma in pigs: role of volume on multiparametric neuromonitoring and histology. J Neurotrauma 25:1107-1119, 2008

66. Umredkar A, Gupta SK, Khandelwal N, Chhabra R, Mathuriya SN, Pathak A, et al: Intracerebral infarcts following clipping of intracranial aneurysms: incidence, clinical correlation and outcome. Br J Neurosurg 24:156-162, 2010

67. Wiebers DO, Whisnant JP, Huston J III, Meissner I, Brown RD Jr, Piepgras DG, et al: Unruptured intracranial aneurysms: natural history, clinical outcome, and risks of surgical and endovascular treatment. Lancet 362:103-110, 2003

68. Yeon JY, Seo DW, Hong SC, Kim JS: Transcranial motor evoked potential monitoring during the surgical clipping of unruptured intracranial aneurysms. J Neurol Sci 293:29-34, 2010

69. Yue Q, Zhu W, Gu Y, Xu B, Lang L, Song J, et al: Motor evoked potential monitoring during surgery of middle cerebral artery aneurysms: a cohort study. World Neurosurg 82:1091-1099, 2014

\section{Disclosures}

The authors report no conflict of interest concerning the materials or methods used in this study or the findings specified in this paper.

\section{Author Contributions}

Conception and design: W Park, Chung. Acquisition of data: Chung. Analysis and interpretation of data: W Park, Chung. Drafting the article: Chung. Critically revising the article: W Park, Hong, JC Park, Ahn, Lee, Kim. Reviewed submitted version of manuscript: W Park, Chung, Hong, JC Park, Ahn, Kwun, Lee, Kim. Statistical analysis: Chung, Kwun. Administrative/technical/ material support: Jeon.

\section{Correspondence}

Wonhyoung Park: University of Ulsan College of Medicine, Asan Medical Center, Seoul, Korea. elevenes@gmail.com. 